\title{
Recent Developments in Remote Document Supply in the UK
}

\author{
Stephen Prowse
}

\section{Introduction}

Looking back over the last few years to see what's been happening in the world of interlending and document supply in the UK, it's clear there have been some groundbreaking developments. Two recent papers from Baker report on how the traditional ILL model is changing into a number of different models as a result of technological and environmental factors (Baker, 2002, 2003). On the other hand we can see evidence of 'business as usual'. It also seems as though some things have taken an awfully long while to happen.

\section{Navel Gazing}

What's not new is a debate of what to call the process of inter-library loans. I suspect this started around the time that the first photocopy was supplied to a requesting library. However I wouldn't be surprised to learn that the debate can actually be traced back to the time of the ancient library of Alexandria, when a piece of papyrus was hand copied for an off-site requester. Whatever the origin, the suitability of terminology such as ILL, interlending, document delivery etc. to describe the processes reported in this journal has been a constant topic of debate over the years, even reflected in changes to the title of the journal itself. A new term of 'remote document supply' (RDS) has been suggested, along with the admonishment not to use other terms except a very restricted use of 'ILL' (Line, 2003). The editor has requested letters on the subject. I must confess the accuracy and appropriateness of ILL terminology has never been a subject to raise my passions, so I am happy to comply with any sensible suggestion, as can be seen in my choice of article title. Now I've just got to remember for the rest of this piece.

\section{Statute Books}

Waiting for the UK implementation of the European Copyright Directive has at times seemed like waiting for Godot but at least it is now here, having come into force on $31^{\text {st }}$ October 2003 (Statutory Instrument 2003 No. 2498). Not that we can all rejoice and say it's been worth the wait. The key change required by the Directive, and the one that has been receiving the most attention, is the distinction now to be made between requesting for commercial and noncommercial purposes. As is usual with copyright, any change begs more questions than answers. However the British Library (BL) and the Libraries and Archives Copyright Alliance (LACA) have attempted to address fears and worries via their websites. The BL provides a very useful list of scenarios that users and libraries will face in deciding whether a request can be said to be for commercial use. And what if one requires an article for commercial use? Well, BLDSC provides a Copyright Fee Paid service, but if the article is not available via that route then users and libraries have more of a problem. Other commercial suppliers may be able to provide, or perhaps publishers can be approached directly, or articles may be obtained under the terms of a CLA licence. It's possible that other libraries may set themselves up as appropriate suppliers. Whatever the alternative, it certainly won't be easy and it's quite likely that many such requests will go unfilled.

A rather more welcome piece of legislation also found its way onto the statute books on the same date as the Directive. This is the Legal Deposit Libraries Act 2003 and it paves the way for the deposit of materials in electronic and non-print form, including web sites (Legal Deposit Libraries Act 2003). Six legal deposit libraries (the BL and the national libraries of Wales and Scotland, Cambridge University, Oxford University and Trinity College Dublin) 
have been entitled, since 1911, to receive a copy of every printed publication distributed in the UK. Any visitor to these libraries will be aware of the space problems and issues of access rights that arise from this right. Space problems and access rights of a different sort will result from the archiving of millions of electronic publications. If we want an idea of the scale of the storage required, and what it would mean to consult archive copies of web pages, then we can take a look at the Wayback Machine hosted by the Internet Archive in San Francisco. This is a great site and it is fascinating to type in a URL of a much-loved site and see what it looked like several years ago. A FAQ provides the following information - "The Internet Archive Wayback Machine contains over 300 terabytes of data and is currently growing at a rate of 12 terabytes per month. This eclipses the amount of text contained in the world's largest libraries, including the Library of Congress” (Internet Archive, no date).

\section{Are we nearly there yet?}

Mention copyright to RDS staff and before long you find yourself discussing electronic signatures. Are they legal? Can we use them? The answer to the first question is 'yes', but curiously this doesn't seem to help much. There seems to be a general consensus that just because electronic signatures are legal that doesn't mean that you can use them. Why is this and why are we so worked up about it?

The Electronic Communications Act 2000 made electronic signatures legal. Rather than celebrating the fact that a long-held dream was now reality, librarians wondered if perhaps they were still dreaming. As reported by Sandy Norman (Norman, 2002), a delegation from LACA met with the Copyright Directorate of the Patent Office to see if electronic signatures could really be used in a library context (such as for RDS), and if existing legislation needed changing. As Sandy says "The Patent Office took over a year to think about it”. Now perhaps this decision required many meetings and consultations, deep thought and analysis, but I think not. For not only did the Patent Office confirm that electronic signatures are acceptable, but that the existing legislation was fine and didn't require amendment. Electronic signatures just have to be personal. Determined to snatch defeat from the jaws of victory, many librarians feel that only a system encrypted to the nth degree can satisfy this requirement. In an environment where the liberal interpretation of copyright laws is being encouraged e.g. the Open Archives movement, it seems to me anomalous, if not perverse, that librarians should resist the clear intentions of the Act.

At King's College London we have been using electronic signatures for some time. RDS requests are made by readers via our webopac using unique and personal user IDs and PINs. By submitting the request a reader is agreeing to a copyright statement at the bottom of the webform. This covers permitted use e.g. for a non-commercial purpose, and together with the ID and PIN acts as the electronic signature. Is this secure enough to satisfy the most stringent demands? Possibly not, but then, when we hear regular reports of hackers breaking into sophisticated systems, could anything ever be? What are librarians hoping to achieve in any case? If we are trying to prevent unauthorised access to material then that is a valid objective. However that isn't the case - for we are saying to readers that they are entitled to material but only if they put pen to paper. If they click on a mouse they can't have it. Apart from annoying readers what does this achieve? Why are we not so concerned about readers forging written signatures?

I believe libraries should start accepting electronic signatures from their readers in the manner I have described. If readers can request by paper they should be able to request electronically. 


\section{Planet ejournals}

Meanwhile back on planet ejournals, the only place where a price rise of twice the rate of inflation is seen as a bargain, are we feeling the first shivers from the cold wind of change? The Serials-eNews alert from the United Kingdom Serials Group (UKSG) reported in it's October 2003 issue how stock market analysts at BNP Paribas posted an 'underperform rating' for Reed Elsevier (UKSG, 2003). As far as I can make out this just means the share price won't be expected to shoot up as much as investors are used to, although interestingly the share price did end 2003 considerably lower than when it started. Perhaps this is the offshore breeze heralding the cold wind.

In keeping with the weather metaphor, Elsevier has been at the centre of a storm of protest over changes to its pricing policy for ScienceDirect. What Elsevier is seeking to do is change the model for pricing subscriptions to ejournal content. At the root of the problem lies higher charges for accessing ejournals that are not also held in print by institutions, coupled with severe penalties for cancelling subscriptions. Trouble brewed in the UK during the negotiations for a new NESLI2 deal, that has had its equivalent in Europe and the U.S. Indeed, Cornell University library has decided to bite the bullet and cancel hundreds of Elsevier subscriptions. Harvard University and others have followed suit.

Thankfully a lot more stability has been introduced into the UK ejournals market over recent years by initiatives such as NESLI2, and its predecessors, and the work of the JISC Journals Working Group. Increasing use of the standard Model Licence for example has ensured a more level playing field. However it can still seem as though this playing field is one of shifting sands with moving goalposts. At the time of writing, after a prolonged period of brinkmanship, a two-year NESLI2 deal with Elsevier had finally been struck. This is a very good deal for UK institutions, achieved thanks to the work of the negotiating agent, Content Complete, and the JISC Journals Working Group, supported by the HE community. It is hoped that high level strategic discussions between Elsevier and HE representatives will take place in 2004, so that any transition from one pricing model to another can be effected more smoothly.

This comes at a time when JISC has allocated $£ 150,000$ to publishers to encourage a switch to an open access model for their journals. Such a model relies on payment for publication of papers rather than subscriptions to a collection of issues. A related move is the suggestion that research should be published in open access journals or archives as a funding requirement of the Research Councils.

Anyone closely following the progress of the Elsevier-NESLI2 negotiations could see how | the balance could swing back from subscriptions to RDS following the collapse of a 'big deal'. Not that RDS could hope to fill the yawning chasm resulting from a failed ScienceDirect deal but it can only benefit in such circumstances. Louis Houle has recently outlined how McGill University library in Canada has moved from subscriptions to RDS and shown the savings that can be made. I haven't come across any recent reports of similar initiatives in the UK, which perhaps supports the long-held belief that RDS is not a threat to subscriptions. Indeed, this was the finding from an Ingenta study into the relationship between RDS and journal subscriptions (Ingenta, 2001). Not only is RDS not a threat, but the study found that subscribers requested more articles from their subscribed journals than nonsubscribers. There are a number of reasons of course why subscribers should be doing this missing issues, ripped out pages, etc. - but it does provide proven evidence that RDS is not 
used as a substitute for subscriptions. No doubt the dominance of the 'big deal' for electronic journals also plays a significant role here, for the inclusion of 'peripheral' titles in a bundle militates against RDS. But if future deals move towards a 'pick and choose' model then we can see libraries focusing on the 'core' titles and leaving the 'peripheral' titles to RDS. While librarians have generally expressed a preference for more control over which titles they subscribe to in ejournal deals, it remains to be seen whether a) 'big deal' publishers make such an option a realistic alternative, and b) whether such a time-consuming activity, as deciding on titles, can fit into librarians' timetables of subscription and renewal.

Shortly before Christmas a press release from the House of Commons announced that the Science and Technology Committee would be conducting an inquiry into scientific publications. Submissions have been invited on a number of points including pricing policies, impact of the 'big deal', open access, promoting competition etc. The Committee promises "some very tough questions for publishers, libraries and government on these issues" (House of Commons Select Committee on Science and Technology, 2003). I'm sure many will welcome such an enquiry and feel that it is long overdue.

\section{Life at Boston Spa}

If growing access to ejournals is dampening demand for RDS, as all evidence suggests, then what is BLDSC doing in response? As part of its change management programme BLDSC has been looking at its processes for RDS, leading to a realignment of its different markets. We can now see much greater differentiation between the different sectors of the UK market that BLDSC serves. Academic libraries in the Republic of Ireland were realigned from the rest of the UK academic market into, effectively, foreign requesters, with much higher charges. And commercial libraries, in particular, have been hit with substantial price increases. Requests from foreign libraries are much more profitable for BLDSC so we can expect expansion in that area. BLDSC has also been developing the services it offers to individual requesters. The National Audit Office is currently conducting one of its 'value for money' reviews on the BL, focusing on three areas, one of which is whether the document supply service is meeting the needs of users effectively. A report is expected early in 2004.

The other important activity of note is the investment BLDSC has been making in new technology. Having teamed up with Relais International, slaving over hot photocopiers is a thing of the past. Instead staff can sit at desks using foot-operated scanners to scan articles that can then be transmitted to customers. Relais technology also plays its part in developments in e delivery. At the Online exhibition in 2002 BLDSC unveiled how it plans to offer a secure e delivery service to customers. Articles can be sent to one of the BL's servers with a URL emailed to the requester linking them to the article. The user can then consult the article online, print it out or download a copy. Thanks to Adobe's eBook Reader (now incorporated into Acrobat 6), in combination with Relais technology, the user will not be able to make multiple printouts and email copies to colleagues. Publishers have been after such guarantees for years. If the history of copyright can be seen as a balancing act between providing access to research while protecting rights owners, then the history of RDS can be seen as a similar tension between providing access to research while protecting subscription revenue. The security now being offered is enough to allay fears of publishers that users will abuse the advantages of communication in an electronic world. The days of downloading journal articles and emailing copies to 10,000 of your closest colleagues are over, at least if acquired via BLDSC. Elsevier was one of the first publishers to jump aboard and its participation has no doubt encouraged others. To see how the use of electronic journals in document supply systems have evolved at BLDSC see (Braid 2003).The original service was 
a Copyright Fee Paid service, so had most appeal to commercial libraries. However the Secure Electronic Delivery (SED) service, as it is now known, was launched at Online in 2003 and is offered under library privilege rules. It will be interesting to monitor the take-up by libraries of this service and to see how quickly they allow articles to be supplied directly to users, without feeling the need to access them first. We'll also have to see how quickly users adopt Acrobat 6 and activate the Digital Rights Management (DRM) component. For many, this decision will be out of their hands, dependent on the software policies of their institutions.

\section{Future systems}

Does anyone still read printed journals? Or has your library disposed of them? Just in case your library is not one that has everything available online you may be interested in the development of SUNCAT, the national union catalogue of serials. A pilot service is scheduled for September 2004. While the focus will be on print journals, enabling users and RDS staff to locate holdings as well as allowing participating libraries the facility to download high-quality catalogue records, ejournals will also be included.

RDS was planned to be incorporated into SUNCAT via Docusend - another JISC project that experienced a prolonged period of stasis (six months) until a new Project Manager was recruited. JISC has extended the life of the project so that it will now complete in October 2004, however the nature of the project has changed so that it will now show proof of concept rather than deliver a working system. This is a shame, though perfectly understandable. For a Docusend service we'll have to wait a bit longer.

This is also a shame for LAMDA, since the service was hoping for something of a rebirth in Docusend. Little has been happening in LAMDA, beyond a decline in use of the service as part of the general decline in requesting. Nevertheless, a number of customers remain fiercely loyal to it, even though the factors that initially attracted libraries to the service - Ariel delivery and cheapness - have been largely negated by changes at BLDSC. These changes, coupled with a delayed Docusend service, mean that LAMDA's future is uncertain.

Talking of waiting for things to happen naturally brings me to the ISO ILL protocol. Where are all the systems from commercial suppliers that have incorporated it? For most it's still in development and yet to be implemented. Thankfully though I can report some good news where progress has been made. OCLC have an ISO ILL-compliant system, although not a lot of UK libraries use it. ILL Manager from RLG is another ISO system that's starting to get a foothold. It's being used by academic libraries that have moved over from RLIN ILL when that system was terminated in August 2003. Other libraries that were using RLIN ILL to take part in the international SHARES programme have had to take a leave of absence, simply because they wanted to use just one system rather than two, as had been the case, and their own library management systems were lacking ISO ILL functionality. But prize for running far ahead of the field must go to FDI's ISO ILL-compliant VDX system and its use by Essex libraries in the Co-East region. How good it is to see public libraries leading the way on a RDS initiative.

Other systems in the news - OCLC PICA has taken on development of V3.Web. This system originated with LASER before passing briefly to LIBPAC. The ILLOS system, developed by Lancaster University, released its final version under its current incarnation in October 2003. A new generation system - ILLOS-NG - is now under development, with a possible release in 2005. 


\section{Future infrastructure}

Two reports were produced in 2003 that look to shape the future of UK research provision. Although the focus for both was very much on HE, other sectors are likely to feel the impact.

The final report of the Research Support Libraries Group (RSLG) recommended setting up a Research Libraries Network. It stressed the importance of document supply and the importance within that field of the British Library. (RSLG, 2003) I think it's worth quoting a paragraph and two recommendations from the report to highlight this.

"The facilities for researchers to obtain copies of relatively short items (especially journal articles), and to borrow monographs and other printed materials not held in their "home" library, are a very significant part of the research information landscape. We believe these facilities (particularly document supply) have been an important element in achieving the UK's high international standing in research excellence based on a comparatively modest research infrastructure. They will be essential elements in the future pattern of provision that we envisage; we recognise that the volume and pattern of demand for such services is likely to change, but as means of assuring access for all researchers to the largest number and broadest range of resources we can conceive of no better arrangement.”

\section{"We recommend:}

a. that ways should be found to ensure the continuing financial health of the British Library, the National Library of Wales and the National Library of Scotland, to fulfil their roles as guardians of the national collections, including keeping pace with developments in volume and cost in both hard copy and electronic materials.

b. that ways should be found to ensure the continuing financial viability of the British Library's document supply and inter-lending services.”

The Report also welcomed a CURL study into the future of monograph interlending (The Higher Education Consultancy Group \& CHEMS, 2003). This study followed on from two CURL projects into interlending and should be read in conjunction with the RSLG report, since it frequently refers to it. The brief of the consultants was "to recommend the best UK wide monograph interlending infrastructure and associated business model for the higher education research community for the next ten years.” The consultants were encouraged to think widely. An alternative system of monograph ILL has grown in the UK recently thanks to involvement in SHARES. Could SHARES have wider possibilities, beyond libraries belonging to CURL? What role should the BL continue to play? These and similar questions were felt to be important enough for CURL and the BL to commission a study to look at the current and possible future state of monograph ILL in the UK. Like the RSLG report, the CURL report underlined the importance and centrality of BLDSC. Six criteria were identified which any future system should meet and against these nine options were considered. The favoured option was given the name 'BLDSC Plus' since the best part of the existing system - BLDSC - would be retained and keep its central position. Partner libraries, possessing unique research collections, would be invited to join BLDSC in forming a consortium. This body would have its own management board. By taking the best of both worlds - BLDSC \& HE Libraries - a new system will be created that should be a big improvement on the fairly recent model of BLDSC supported by backup libraries. Consultation between BLDSC and HE libraries should also be improved, with any potentially controversial proposals being 
thoroughly discussed before implementation. A small steering group has been set up by CURL to see the Report's recommendations through to fruition. The appointment of a project manager will be one of its first tasks.

\section{Hays DX - the horror, the horror}

If ILL is going to focus on monographs then the need arises to get them from A to B and back again. How to do this cheaply and efficiently poses a problem. The lis-ill mailing list periodically reports a number of horror stories concerning Hays DX, the mail transporting company. The latest series from October 2003 follow the pattern of previous mailings. While a few libraries experience excellent service others report shocking, if nevertheless entertaining, tales of stock being lost, left out in the open after being dumped through iron gates and deposited at the side of a road. The problems have been such that a number of libraries have started to insist that Hays DX is not used to return their books. But having just endured a strike by staff, the Royal Mail isn’t always an attractive or viable alternative.

The various problems associated with transporting monographs have meant that direct delivery to end users has yet to take off, even in libraries with distance learning programmes, whereas delivery of articles is well established. One of the recommendations from the CURL report is that a pilot scheme is set up whereby end users request monographs, directly from libraries, for home delivery. Such a pilot may overcome the inertia associated with monograph ILL but we'll have to see if the postage problem can be solved, or if it is as much of a problem as it appears.

\section{Lost in transition}

In many ways we are in a period of transition. The electronic article is rapidly becoming the article of record, although electronic journals have yet to take full advantage of their difference from print and incorporate other media. Articles are still collected into journals rather than existing in their own right. Library subscriptions to journal packages are often tied to spending on print. Open archives are becoming established but we are seeing institutional rather than subject-based eprint archives. Monograph supply is moving from BLDSC plus others to BLDSC Plus. ISO ILL is yet to take over the world. RDS librarians have not been displaced by end users. But there's obviously plenty of scope for change and enough for RDS watchers to be keeping an eye on.

\section{References}

Baker, D. (2002), "Document delivery: breaking the mould”, Interlending \& Document Supply, Vol. 30 No. 4, pp.171-177.

Baker, D. (2003), “Document delivery: a new paradigm”, Interlending \& Document Supply, Vol. 31 No. 2, pp.104-110.

Braid, A. (2003), “The use of electronic journals in a document delivery service”, Serials, Vol. 16 No. 1, pp.37-40.

The Higher Education Consultancy Group \& CHEMS (2003), A Report to CURL and the British Library Cooperation and Partnership Programme on: Monograph Interlending for the Higher Education Research Community, http://www.curl.ac.uk/projects/Monographfinal.pdf 
House of Commons Select Committee on Science and Technology (2003), Scientific Publications,

http://www.parliament.uk/parliamentary_committees/science_and_technology_committee/sci tech111203a.cfm

Ingenta Institute (2001), Assumptions versus reality: user behaviour in sourcing scholarly information, Ingenta, Oxford.

Internet Archive Wayback Machine FAQ, http://www.archive.org/about/faqs.php

Legal Deposit Libraries Act 2003, HMSO, London,

http://www.legislation.hmso.gov.uk/acts/acts2003/20030028.htm

Line, M.B. (2003), “A matter of terminology: from ILL and DD to RDS”, Interlending \& Document Supply, Vol. 31 No. 2, pp.147-48.

Norman, S. (2002), Electronic signatures on copyright declaration forms, Libraries and Archives Copyright Alliance, http://www.cilip.org.uk/committees/laca/e_sigs.html

Relais International (2003), “The British Library chooses Relais Enterprise”, press release, $9^{\text {th }}$ June, http://www.relais-

intl.com/RelaisInternational/BLDSC\%20press\%20release\%20_for\%20web_pdf

RSLG (2003), Final Report http://www.rslg.ac.uk/

Statutory Instrument 2003 No. 2498, The Copyright and Related Rights Legislation, HMSO, London, http://www.legislation.hmso.gov.uk/si/si2003/20032498.htm

UKSG (2003), “Elsevier stock warning over open access”, Serials-eNews, No. 52, http://www.openrfi.com/UKSG/si_pd.cfm?pid=1 